\title{
Hemoperitoneum caused by hemorrhage of tubal vessels, a previously undescribed complication of colonoscopy
}

A 46-year-old woman underwent colonoscopy due to iron-deficiency anemia. The patient had previously undergone an operation for ovarian endometriomas. During this procedure, when the operator was advancing with the endoscope to the sigmoid colon, the patient suddenly suffered a severe abdominal pain. The exploration was suspended before perforation was suspected.

Physical examination revealed hypogastric abdominal pain with peritoneal irritation. The laboratory test was negative, and the abdominal radiograph excluded pneumoperitoneum ( $\bullet$ Fig. 1).

The patient presented for clinical examination of acute abdominal pain, so it was decided to make an emergency laparotomy. During this operation, hemoperitoneum was found ( $150 \mathrm{~mL}$ of blood), two ruptures on the serosa of the sigma with no alteration on the mucosa and submucosa were visualized, and tubal vessel hemorrhage and adherences between the mesosalpinx and mesosigma observed.

The incidence of serious complications due to colonoscopy is low; the percentage of procedures for which complications require hospitalization is $0.21 \%$. Serious complications may be associated with stricture dilation, polypectomy, elderly patients or inexperienced endoscopists [1]. Hemoperitoneum is an uncommon complication of colonoscopy [2]. The most frequent cause of hemoperitoneum is splenic injury, but in the literature there are others causes described, such as rupture of an epiploic appendix [3], torsion of the mesenteric vein [2], necrosis of a small intestinal leiomyosarcoma [4] or

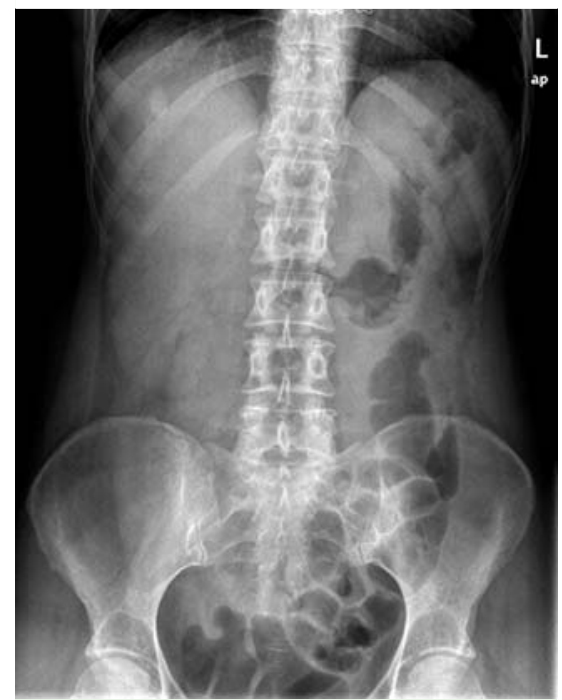

Fig. 1 Abdominal radiograph that excludes pneumoperitoneum.

ovarian tumor rupture [5]. As far as we know, this is the first case of hemoperitoneum caused by rupture of tubal vessels with adherences of the fallopian tube to the sigma.

Endoscopy_UCTN_Code_CPL_1AJ_2AB

Competing interests: None

N. Alcaide ${ }^{1}$, R. Atienza1 , J. Barrio ${ }^{1}$, C. de la Cuesta ${ }^{2}$, M. Pérez-Miranda

1 Department of Gastroenterology, University Hospital Río Hortega, Valladolid, Spain

2 Department of Gastrointestinal Surgery, University Hospital Río Hortega,

Valladolid, Spain

\section{References}

1 Ko CW, Riffle S, Michaels L et al. Serious complications within 30 days of screening and surveillance colonoscopy are uncommon. Clin Gastroenterol Hepatol 2010; 8: 166 173 [Epub 2009 Oct 20]

2 Tagg W, Woods S, Razdan R et al. Hemoperitoneum after colonoscopy. Endoscopy 2008; 40: E136-E137 [Epub 2008 Jul 16]

3 Sorrentino M, Terrosu G, Risaliti A et al. Hemoperitoneum caused by lesions to the appendix epiploica. An unusual complication of colonoscopy. Minerva Chir 1996; 51: $835-837$

4 Gonzalez-Rodriguez JF, Tarquis-Alonso P, Castano-Pascual A, Gonzalez-Lera S. Hemoperitoneum due to necrosis of a small intestinal leiomyosarcoma following colonoscopy. Endoscopy 1993; 25: 253-254

5 Fusaroli P, Maltoni S, Eusebi V et al. Ovarian tumor rupture causing massive hemoperitoneum: an unusual complication of colonoscopy. Gastrointest Endosc 2008; 67: 1177 - 1178 [Epub 2008 Apr 18]

\section{Bibliography}

DoI $10.1055 / \mathrm{s}-0030-1256025$

Endoscopy 2011; 43: E93

(c) Georg Thieme Verlag KG Stuttgart · New York . ISSN 0013-726X

\section{Corresponding author}

\section{N. Alcaide, MD}

Deparment of Gastroenterology Hospital Universitario Río Hortega

C/Dulzaina 2

47012 Valladolid

Spain

Fax: +34-983-420400

noelialcaide@hotmail.com 